\title{
Self-organization and complexity in historical landscape patterns
}

\author{
Janine Bolliger, Julien C. Sprott and David J. Mladenoff
}

Bolliger, J., Sprott, J. C. and Mladenoff, D. J. 2003. Self-organization and complexity in historical landscape patterns. - Oikos 100: 541-553.

Self-organization describes the evolution process of complex structures where systems emerge spontaneously, driven internally by variations of the system itself. Self-organization to the critical state is manifested by scale-free behavior across many orders of magnitude (Bak et al. 1987, Bak 1996, Solé et al. 1999). Spatial scale-free behavior implies fractal properties and is quantified by the fractal dimension. Temporal scale-free behavior is evident in power spectra of fluctuations that obey power laws. Self-organized criticality is a universal phenomenon that likely produces some of the fractals and power laws observed in nature.

We investigated the historical landscape of southern Wisconsin (USA) $(60,000$ $\mathrm{km}^{2}$ ) for self-organization and complexity. The landscape is patterned into prairies, savannas, and open and closed forests, using data from the United States General Land Office Surveys that were conducted during the 19th century, at a time prior to Euro-American settlement.

We applied a two-dimensional cellular automaton model with one adjustable parameter. Model evolution replaces a cell that dies at random times by a cell chosen randomly from within a circular radius $r$, where $r$ typically takes values between 1 (local) and 10 units (regional). Cluster probability is used to measure the degree of organization. The model landscape self-organizes to a realistic critical state if neighborhoods of intermediate size $(r=3)$ are chosen, indicating that (a) no particular time or space scale for the clusters is singled out, i.e. the spatial dependence is fractal, and temporal fluctuations in the cluster probability exhibit power laws; (b) a simple model suffices to replicate the landscape pattern resulting from complex spatial and temporal interactions.

Measures of comparison between the observed and the simulated landscape show good agreement: fractal dimensions for simulated (1.6) and observed landscapes (1.64), cluster probabilities for simulated $(32.3 \%)$ and observed $(32.6 \%)$ landscapes, and algorithmic complexity for simulated (6792 bytes) and observed (6205 bytes) landscapes. The results are robust towards variation of initial and boundary conditions as well as perturbations.

J. Bolliger and D. J. Mladenoff, Dept of Forest Ecology and Management, Univ. of Wisconsin-Madison, Madison, WI 53706, USA ( present address of JB: Swiss Federal Research Institute (WSL), Zürcherstrasse 111, CH-8903 Birmensdorf, Switzerland [janine.bolliger@wsl.ch])._J.C. Sprott, Dept of Physics, Univ. of WisconsinMadison, Madison, WI 53706, USA.

Ecological systems show complex patterns and behavior in space and time (Klomp and Green 1996, Bradbury et al. 2000, Gisiger 2001). This spatio-temporal complexity can be described using various approaches. Among those, models have been widely used to improve the understanding and predictions of observed ecosystem function, pattern or diversity.
Exogeneous models predict details on the behavior of individual biotic units (e.g. ecosystem, tree-species) as a function of details of the external heterogeneity (e.g. climate, soil, disturbance) whose specific environmental processes are mirrored using complex and detailed model parameters. This autecological approach is usually strongly reductionist, since the ecosystem under

Accepted 29 August 2002

Copyright (C) OIKOS 2003

ISSN 0030-1299

OIKOS 100:3 (2003) 
study is analyzed for its most likely exernal driving forces. In exogeneous models, the temporal and spatial scale of the external heterogeneity usually relate to particular spatial or temporal scales of the biotic unit. The scales range from biomes (Holdridge 1947, Prentice et al. 1992, Kirilenko and Solomon 1998), ecosystems (Beerling et al. 1997), or vegetation types (Brown 1994a, Zimmermann and Kienast 1999), to individual species (Huntley et al. 1995, Bugmann 1996, Iverson and Prasad 1998, He and Mladenoff 1999, Bolliger et al. 2000). Such simulations, where the properties of the simulated biotic units directly relate to the spatial or temporal scale of the external heterogeneity, are called scale-variant.

Simulations from exogeneous models are most realistic when they encompass the behavior of individual biotic units in births, deaths, and movements (Pacala et al. 1996). The simulations then exhibit complex spatiotemporal behavior. However, when simulating large spatial scales, (e.g. landscapes), the general representation of the results (e.g. landscape pattern) may be of more interest than details of locations, processes, or behavior of individuals, especially as corresponding data on spatio-temporal details are often incomplete on large scales.

General large-scale representations can be achieved using endogeneous modeling approaches, an alternative approach to exogeneous models that rely on the variation and the internal interaction between the biotic units rather than on external heterogeneity. Typically, the parameters found in such models are very simple and generic in the sense that not much information is needed, rather than detailed and specific as in exogeneous models. Also, the system properties found with endogeneous models are regarded as universal, i.e. they allow generalization of properties across various levels of organization while accounting for the properties observed at each hierarchical level (Brown 1994b). This implies that the properties are true for all hierarchical level (large to small scale), indicating that the simulated ecosystem does not have any particular space or time scale. Such scale-free behavior is called scale-invariant.

The dynamics between the components of an exogeneous system cause organization by accumulation of small changes (Bak 1996). Evolution of these changes in succeeding generations allows gradual development that eventually generates to order and complex features that are more than the sum of the individual parts of the system. This process is called self-organization. Self-organization addresses the question of how interactions between system structure and processes grow to generate order in large-scale multi-component (complex) systems (Perry 1995, Bradbury et al. 2000). This synecologial approach views system components as non-linearly interacting parts of larger system structures. A system organizes to a critical state if the dynamics of a system lead it to a complex state. This state is usually characterized by spatial scale invariance (fractals) and temporal scale invariance (power laws) (Bak et al. 1987, Bak 1996), thus the system exhibits no characteristic space or time scale. Such states are called self-organized critical (Bak et al. 1987, Bak 1996, Solé et al. 1999). Because scale invariance involves longrange correlations, the phenomenon may also reflect some key features of how systems are organized and how they evolve in time.

In this paper, we analyze self-organizing aggregation in a complex landscape and quantify the resulting landscape complexity based on information theory (algorithmic complexity) using the historical landscape of southern Wisconsin (USA) as an example. We hypothesize that complex spatio-temporal phenomena such as the evolution of landscape pattern can be sufficiently described by an endogeneous model with a single parameter, and that landscape complexity need not require by complex model constructions.

\section{Material and methods}

\section{Study area}

The study area covers the southern part of Wisconsin (USA), encompassing approximately $60000 \mathrm{~km}^{2}$ (Fig. 1). Prior to Euro-American settlement, the landscape of southern Wisconsin was patternend into prairie, savannas and forests, most likely as a function of different fire regimes (Curtis 1959, Finley 1976, Whitney 1994).

The climate is generally continental, and conditions range from warm and humid summers to cold and dry winters. The climatic pattern is driven by three contrasting air masses: cool-temperate air from the Pacific via the Rocky Mountains, subtropical air from the Gulf of Mexico, as well as arctic air masses from Canada.

Major landscape features such as moraines or outwash plains are of glacial origin. The southwestern part of the state (Driftless area), however, has not been glaciated in recent episodes, and is thus characterized by finely dissected topographical features. Early descriptions picture the widespread occurrence of different species of oaks (Quercus ssp.) on hills, and on dry sites. Sand barrens were dominated by pines and oaks. Mesic hardwood and lowland forests occurred on richer, well-drained soils in the Driftless area and on more temperate sites along the Lake Michigan shore.

\section{The historic U.S. General Land Office Survey database}

The historical landscape of southern Wisconsin is represented by the United States General Land Office Surveys. The surveys were carried out in the 19th century from Ohio to the west coast of the United States. In Wisconsin, the U.S. General Land Office Surveys were 
Fig. 1. The study area of southern Wisconsin (USA) prior to Euro-American settlement.

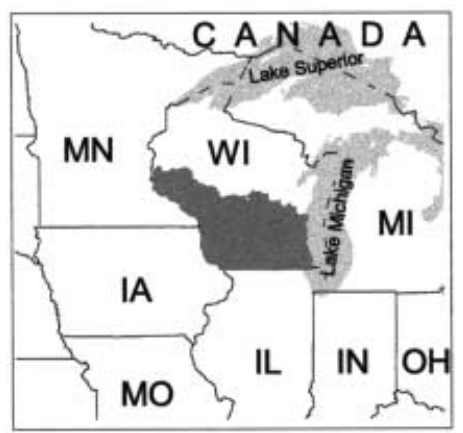

Closed forest

Open woodland

Savanna

Tamarack swamp

Prairie

Lake Winnebago

No data

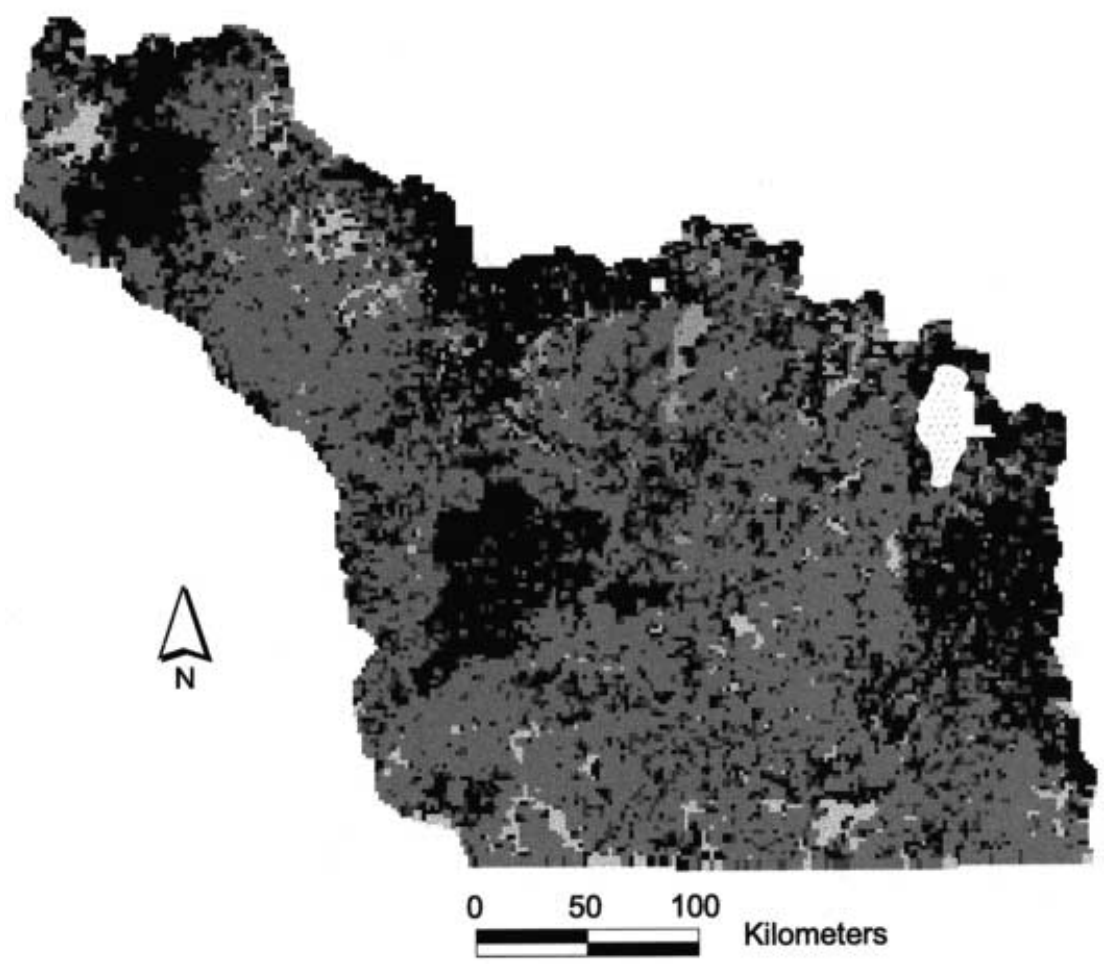

conducted between 1832 and 1866 (Stewart 1935). The land was divided into township grids, each consisting of 361 -mile $\left(1.6 \times 1.6 \mathrm{~km}^{2}\right)$ sections. Survey posts were set every half mile (quarter section corners), and every full mile (section corners). Typically, one to four trees near the posts were blazed (witness trees) to mark the section and quarter section corner post locations. The witness tree species, diameter, and distance to the corner were recorded. Additionally, line trees situated between the section and the quarter section corners were noted by species, diameter, and distance from the corner. Meander posts were set when the surveyors crossed rivers and lakes. Descriptive notes on ecosystem properties such as swamps, burns, or windfall were recorded, and occasionally sketched. In spite of various biases and constraints (Manies and Mladenoff 2000, Manies et al. 2001, Mladenoff et al. 2002), the surveys are widely recognized to provide a reliable basis for large-scale quantitative and qualitative information on landscapes prior to EuroAmerican settlement.

The surveys have been widely used to address a broad range of scientific questions such as reconstructing historical landscapes (Rodgers and Anderson 1979, Nelson 1997, Russell 1997, Radeloff et al. 2000b, Schulte and Mladenoff 2001; Schulte et al. 2002), landscape classification (Brown 1998a, b, Manies and Mladenoff 2000), historical landscape-scale disturbance events such as wind (Canham and Loucks 1984, Zhang et al. 1999), or fire (Kline and Cottam 1979, Grimm 1984), or analysis of the historic landscape pattern and their change (Auclair 1976, Mladenoff and Howell 1980, Mikan et al. 1994, White and Mladenoff 1994, Wallin et al. 1996, Radeloff et al. 1999), as well as research on the anthropogenic role of land-use change (Russell 1981, 1997, Foster et al. 1998, Bürgi et al. 2000, Bürgi and Russell 2001), or early socio-economic trends (Silbernagel et al. 1997). 
Table 1. Frequencies of the historical landscape patterns (number of cells and percent of total landscape).

\begin{tabular}{lllll}
\hline Closed forest & Open woodland & Savanna & Tamarack swamps & Prairie \\
\hline $8367(30.2)$ & $3727(13.5)$ & $14058(50.8)$ & $632(2.3)$ & $877(3.2)$ \\
\hline
\end{tabular}

The set of original field notes for the entire state of Wisconsin was digitally compiled for the purpose of ecological analysis and mapping (Sickley 2000). The tabular point database contains information on the tree species and diameter, tree distances from the section corners, and quarter section corner posts, line trees, and meander corners. The descriptive surveyor notes on the ecosystem characteristics were also compiled. For more information on methodological details on the survey as well as on the database, see Sickley (2000).

To conduct this study, we used tree density information from all types of corners (section, quarter section, line, and meander corners).

\section{Historical landscape pattern}

Prior to Euro-American settlement, the landscape of southern Wisconsin consisted of primarily four major vegetation types: prairies, savannas, and open and closed forests, mainly dominated by deciduous trees. The vegetation pattern is a continuum rather than discrete units, and probably the result from differing fire regimes (Curtis 1959, Finley 1976, Whitney 1994). The landscape pattern was mimicked using tree-density information derived from the U.S. General Land Office Surveys.

The tree densities were derived using the AVMwindows moving windows program that calculates a variety of vegetation indices (tree dominance, density, relative importance values) based on the basal area of trees (He et al. 2000). All indices are available at a variety of user-defined spatial scales (He et al. 2000). We employed a measure for tree density that is calculated as the average densities of all witness trees within 1 square mile, according to a method developed by Cottam and Curtis (1956). We chose a 1-mile resolution to resemble the original 1-mile resolution of the surveys.

The tree densities were then used to distinguish landscape patterns according to a classification developed for a landscape similar to southern Wisconsin by Anderson and Anderson (1975): prairie ( $<0.5$ trees/ha), savanna (0.5-46 trees/ha), open woodland (46-99 trees/ha), and closed forest ( $>99$ trees/ha), where 1 ha $=1 \times 10^{4} \mathrm{~m}^{2}$. Additionally, we categorized pixels dominated by tamaracks as tamarack-swamps and included a category for missing data. The historical landscape of southern Wisconsin was dominated by far by savanna-type vegetation, followed by closed and open woodlands, prairies and swamps (Table 1).

\section{Single-parameter cellular automaton model}

Cellular automata are spatially extended discrete dynamic systems that are based on regular arrays of cells. The cells take $n$ possible states and are usually updated simultaneously in discrete time steps. Typically, a cell's evolution depends on the states of neighboring cells, and the global evolution of the cellular automaton is driven by these local interactions.

In our case, the spatial extension of the two-dimensional square lattice cellular automaton embraces the landscape of southern Wisconsin (Fig. 1). The model consists of a rectangular array of $253 \times 202$ cells. The cells have a size of 1-square mile to resemble the resolution of the survey data. For interpretation of the simulation results, only those cells in the array are diagnosed that overlap the experimental region, although all cells in the rectangular array are evolved.

Each cell has one of six values (representing prairie, savanna, open or closed forest, tamarack swamp, or missing data) chosen with the same initial probability as the observed data. For very long simulations, there is a tendency for the minority categories to become extinct. To prevent that from happening, the replacements are made with a probability slightly less than $100 \%$ that is continually adjusted to keep the probability of each category approximately constant, allowing long-term simulations. In doing so, we constrain the proportions of the landscape pattern to stay constant through time, i.e. the environmental constraints that shape the landscape (fire, wind, climate) do not change through time. Thus we are not attempting to predict the probability of the various landscape types, but only the spatio-temporal behavior of a landscape with the observed probabilities.

The rule for landscape evolution is extremely simple in that no biological detail is required. At each time step, a randomly chosen cell in the array is replaced by a cell chosen randomly from its circular neighborhood of radius $r$ (measured in units of the cell size) where $r$ is the only parameter of the model measured in units of the lattice spacing. The radius $r$ may take values between 1 (local) and 10 (regional) units. The $r=1$ unit case includes 4 , the $r=3$ case includes 28 , and the $r=10$ case includes 316 grid cells. After 51,106 time steps, each cell in the array has been replaced once on average. This time is referred to as a generation. It should correspond roughly to the average life of a tree, on the order of 100 years.

This method differs from other cellular automata where all cells are updated simultaneously. We chose 
the method for computational convenience and because it better represents real forest evolution where trees die somewhat randomly. Tests indicate no significant dependence on the order in which cells are updated. Our cellular automaton resembles the voter model (Clifford and Sudbury 1973, Holley and Liggett 1975) that has been used to model the behavior of a particularly impressionable population in a series of political elections

\section{Measures for model robustness}

We tested the model's behavior across a range of conditions. The robustness of the simulations was tested for model characteristics such as (1) initial conditions (random and highly ordered, shown in Fig. 2a, b), and (2) boundary conditions (periodic and reflecting). With periodic boundary conditions the landscape boundaries are folded into a torus. With reflecting boundary conditions the landscape boundaries are mirror imaged i.e. a cell at the rightmost edge of the grid is assumed to have a neighbor on its right that is the same as on its left, similarly for the other edges top, bottom, and left.

We also tested the robustness of the simulations towards the abundance of the original landscape-pattern frequencies used to initiate the model. The original landscape-pattern frequency is shown in Table 1 with savanna as the most frequent pattern, followed by closed forest open woodland, prairie and swamp. The first perturbation experiment varies these original proportions of the landscape patterns so that the most frequent landscape type savanna is increased $20 \%$ and all the other landscape types (closed and open woodland, prairie, swamp) are decreased $20 \%$ in their frequencies. Simulations after convergence resulting from the perturbed and the unperturbed data set are then compared. In a second perturbation experiment the landscape types are randomly changed into cells with different landscape types for selected cells. The number of cells perturbed in this manner ranges from a single cell to about half of the cell total (corresponding to approximately 14000 cells). The effect of these pertur-

\section{(a) random}

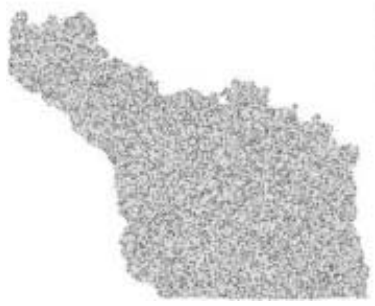

\section{(b) ordered}

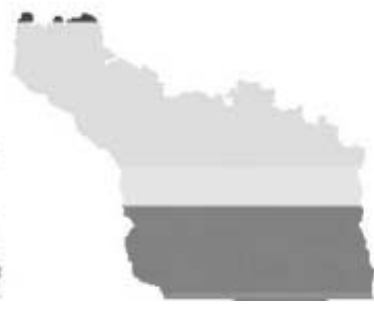

Fig. 2. Random (a) and ordered (b) initial conditions of the cellular automation. bations on the landscape-pattern development is followed through time: Dying perturbations (i.e. decrease in perturbed cells) indicate low sensitivity to the perturbation, whereas growing perturbations (i.e. increase in perturbed cells) over time indicate strong sensitivity to the perturbation.

In a third robustness test, we investigated at the model's sensitivity to the original 1-square mile grid size by resampling the data on various grid sizes ranging from 2 to 8 miles.

\section{Model runs}

Model simulations were run five times for each boundary condition (periodic and reflecting), and for each initial condition (random and ordered) for radii of $r=1,3$, and 10 units. The simulations were run for a period of about 30,000 generations, resulting in a simulated period of about 3 million years. Averages and standard deviations of the five runs were used to plot the behavior of the evolving cellular automaton through time.

\section{Measures of comparison between simulated and observed landscapes}

We compared the simulated to the observed landscape using three measures: fractal dimension, cluster probability, and algorithmic complexity.

\section{Fractal dimension and spatial scale-invariance}

Fractal geometry is used to compare properties of the spatial structures of simulated and observed landscapes since they quantify the spatial complexity apparent in landscapes (Mandelbrot 1982, Gardner et al. 1987, Milne 1988, 1991, O’Neill et al. 1988, Sprott et al. 2002). Fractals are mathematical representations of complex natural patterns (e.g. sea shores) and provide measures of spatial dependence at a variety of scales. They are described using algorithms that quantify the proportion of the geometrical space that is occupied by the fractal. Here, we applied a variant of the Grassberger-Procaccia algorithm to quantify the total structure of the landscape (Grassberger and Procaccia 1983). The fractal dimension is calculated using correlation sums. The correlation sum $C(\varepsilon)$ is defined as the probability that two randomly chosen points of the same landscape type (e.g. prairie) are within a distance $\varepsilon$ of one another, where $\varepsilon$ is taken as the maximum norm $\left|x_{1}-x_{2}\right|+\left|y_{1}-y_{2}\right|$ rather than the usual Euclidean norm.

To assess the pattern-size scale invariance, the log of the correlation sum $C(\varepsilon)$ is plotted versus the $\log$ of the scale size $\varepsilon$. The range of $\varepsilon$ over which the plot is a straight line is the scaling region, and the slope of the 
line $d \log C(\varepsilon) / d \log \varepsilon$ is the correlation dimension. The correlation dimension is one measure of the fractal dimension and a point of comparison between model and observations.

Power laws are usually referred to as a footprint of self-organization to a critical state. In a spatial context, this indicates that the landscape is dominated by a few large, and many small clusters. The observations on any scale allow predictions on all scales.

Cluster probability and temporal scale-invariance $\left(1 / f^{\alpha}\right.$ power laws)

Cluster probability is used to measure organization and the temporal behavior of the simulated landscape. It is defined as the portion of cells that are part of a cluster on the entire array of cells. A point in the array is assumed to be part of a cluster if its four nearest neighbors are the same as it is. A highly disorganized array has a small cluster probability, and a highly organized array has a large cluster probability. The cluster probability i.e. the portion of cells that are part of a cluster across the entire region is $32.3 \%$ for the observed landscape (Fig. 1).

Cluster probability was used to assess the temporal scale-invariance as evidenced by $1 / \mathrm{f}$ temporal fluctuations in power spectra that are considered to be one of the indications of self-organized criticality. In a temporal context, $1 / \mathrm{f}^{\alpha}$ power-laws indicate that no characteristic frequencies or time scales exist.

The power spectrum was derived using software developed by Sprott and Rowlands (1998). $P(f)$ of a signal $h(t)$ is defined as the contribution of each frequency $f$ to the signal $h(t) .1 / \mathrm{f}^{\alpha}$ power spectra contain all frequencies with the predominance at the lowest frequencies.

\section{Algorithmic complexity}

Algorithmic complexity is used to compare the complexity of the observed and the simulated landscapes and is defined as the size of the simplest computational (a)

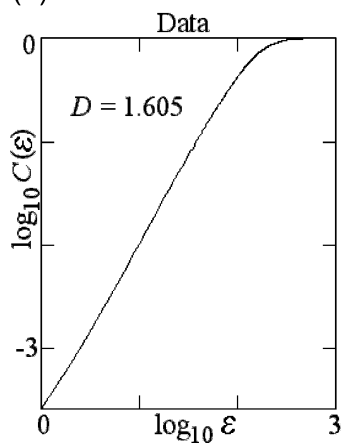

(b)

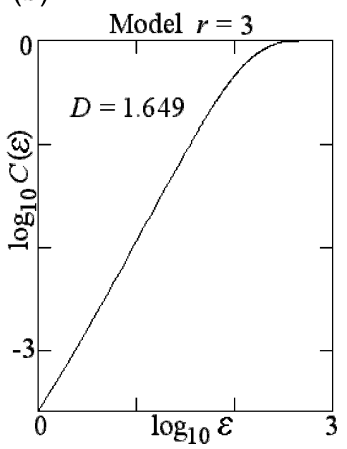

Fig. 3. Fractal dimension as a measure of comparison between (a) observed and (b) simulated landscape patterns. algorithm that is able to reproduce the data. With this approach, condensation of the entire set of interactions between system components is achieved (Lempel and Ziv 1976, Kaspar and Schuster 1987, Manson 2001). One way to estimate this quantity takes advantage of the fact that GIF graphic files are nearly optimally compressed. The algorithmic complexity of the landscape-pattern graphics is determined by the size of the GIF file of the landscape image after subtracting the fixed size of the file header (Sprott et al. 2002). Although this measure is subject to debate (Feldman and Crutchfield 1998), it provides a comparison between simulations and observations.

\section{Results}

\section{Measures for comparison between observed and simulated landscape}

Spatial scale-invariance ( fractals)

The fractal dimension (slope of the graph) for both the observed and simulated landscape for $r=3$ after convergence is about 1.6 , indicating that the spatial properties of the observed landscape are well reproduced by the model (Fig. 3a, b).

The curves in Fig. $3 a$ and $b$ do not change its slope from the smallest scale up to the scale of the entire landscape. This indicates no particular spatial scale is singled out and that a pattern has the same properties when observed at different spatial resolutions. This property is referred to as spatial scale invariance, meaning that the landscape is a fractal (self-similar on scales across several orders of magnitude).

\section{Temporal scale invariance}

The measure for organization of the landscape, cluster probability, is $32.3 \%$ for the observed landscape (Fig. $4 \mathrm{a}$ and $\mathrm{b}$ ), indicating that $32.3 \%$ of the cells are part of clusters that ultimately form the observed landscape pattern in Fig. 1.

The different sizes of neighborhoods (radius sizes) used in the model can be viewed as a measure of the distance over which cells interact with each other. Choosing small neighborhoods $(r=1$ corresponding to 4 neighboring cells), results in over-organization of the landscape (Fig. 4a and b), i.e. it reaches a higher percentage of clustered cells $(68.9 \%)$ than the observed landscape $(32.3 \%)$. Since cells within a small neighborhood are more likely to exhibit similar features, and since local interactions due to small radii sizes allow only limited connection with the entire set of features occurring on the landscape, it is more likely that evolving cells find cells with the same features, and thus over-organize. 
If large neighborhoods ( $r=10$ corresponding to 316 neighboring cells) are chosen, the simulated landscape does not self-organize, exhibiting a cluster probability less than 10\% (Fig. 4a and b). Large neighborhoods account for the overall landscape-pattern diversity. In such cases the likelihood that cells with identical properties interact is small since such cells are often found adjacent to each other.

If intermediate neighborhoods $(r=3$ corresponding to 28 neighboring cells) are chosen, however, self-organization of the landscape to the observed value of $32.3 \%$ (Fig. $4 \mathrm{a}$ and $\mathrm{b}$ ). Intermediate neighborhood sizes appear thus to account for large enough landscape-pattern diversity to allow occasional larger-distance interactions, in addition to the small-scale interactions between neighbors.

The effect of the neighborhood sizes on the self-organization of the landscape is independent of the initial

\section{(a)}

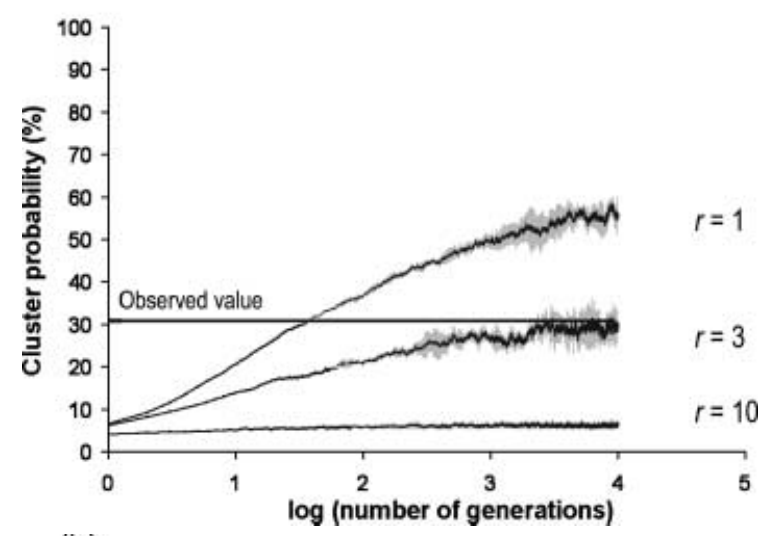

(b)

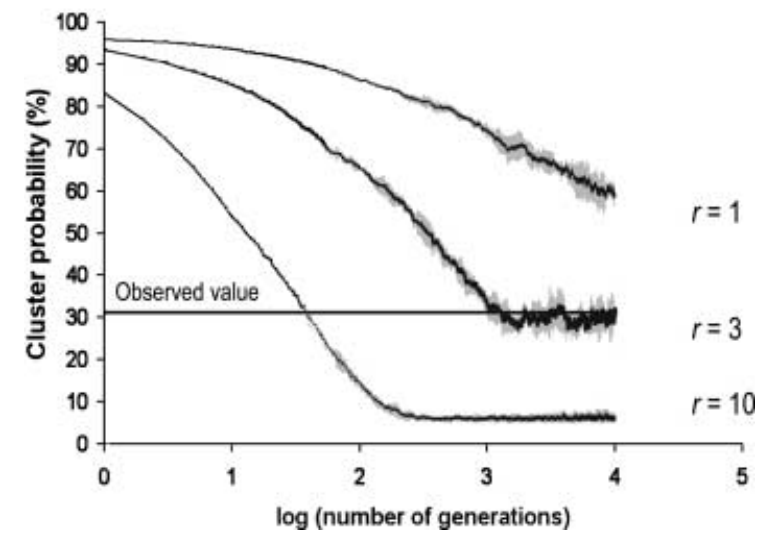

Fig. 4. Cluster probability as a measure of comparison between observed and simulated landscape patterns. The landscape evolves with (a) random, and (b) ordered initial conditions to the same level of organisation $(32.3 \%)$ as the observed landscape pattern (cluster probability: $32.3 \%$ ) if an intermediate radius size of $r=3$ is chosen. Shown are means and standard deviations of five runs. (a)

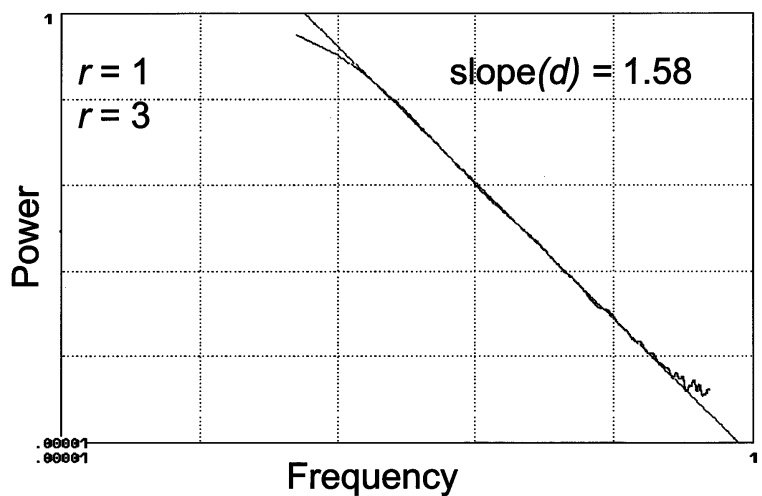

(b)

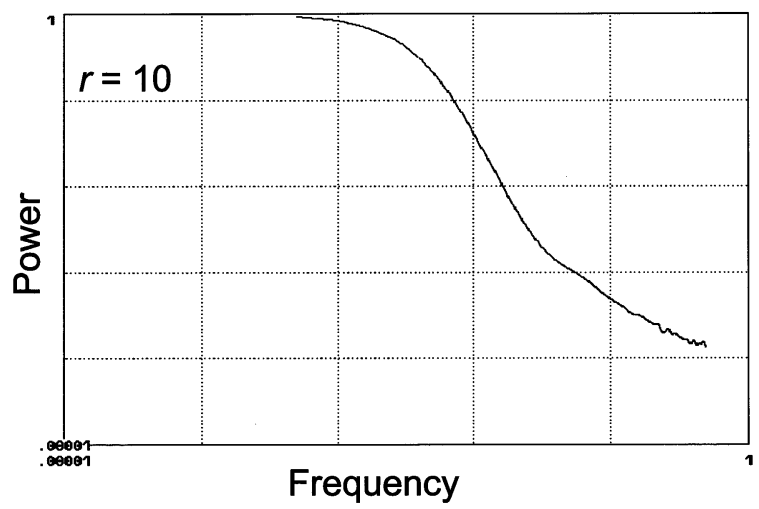

Fig. 5. (a) Power law for the neighborhood sizes of $r=1$ and $r=3$; (b) no power law for the radius size of $r=10$.

conditions. For a completely random landscape in Fig. $4 \mathrm{a}$, order is created (increasing cluster probability) with time. For a completely ordered landscape in Fig. 4b, the order is decreased (decreasing cluster probability).

Analyses of the temporal fluctuations of the cluster probability after convergence for the different sizes of neighborhoods as analyzed in Fig. $4 \mathrm{a}$ and $\mathrm{b}$ are shown in Fig. 5a and b. When plotted on a log-log scale, the power (squares of amplitudes) and the frequency (inverse of the period) of the converged graph of the cluster probability exhibit power-law behavior $1 / \mathrm{f}^{\alpha}$ with $\alpha=1.58$ for $r=1$ and $r=3$ (Fig. 5a). Power spectra that exhibit straight lines are referred to as power laws. The straight line of the power law indicates that no particular time scale is singled out, and the properties of a given frequency stand for all frequencies (scale invariance), indicating that any landscape-pattern change may take place any time and is likely to affect the entire landscape on every temporal scale.

The neighborhood size of $r=10$ does not show power-law behavior (Fig. 5b), as particular time scales are singled out (i.e. the slope changes and the graph is not a straight line). Also, this size of neighborhood strongly under-organizes (Fig. 4a, b), with a cluster probability of $10 \%$ instead of the observed $32.2 \%$. 
Landscape complexity

The GIF file representing the observed landscape in Fig. 1 compresses to 6205 bytes. The self-organized simulated landscape with $r=3$ compresses to a size similar to the observed landscape (6792 bytes) compared to a complete random landscape that compresses to 8136 bytes.

\section{Measures for model robustness}

The results are not sensitive to any of the boundary (periodic, reflecting) - or initial (random, ordered) conditions considered (example shown in Fig. 4a and b), indicating robust behavior towards the initial states of the model. Periodic and reflecting boundary conditions are indistinguishable.

The model exhibits robustness towards variation in the pattern frequencies for the radii that exhibit self-organization of the landscape ( $r=1$ and $r=3$ ) (Fig. 6). The effect of the perturbation is larger for $r=10$ because the landscape remains essentially random (i.e. not self-organizing) and the cluster probability is determined primarily by the relative pattern frequencies.

The model is also robust towards random perturbations of the landscape pattern, because it is only a matter of time until all sizes of perturbation die out. Small perturbations die out relatively quickly, whereas large perturbations die out more slowly (Fig. 7).

Tests of the model's robustness to the original resolution of the input grid by resampling of the original 1 mile square grid at resolutions of 2, 4 and 8 mile grids show cluster probabilities for the self-organized state comparable to the original 1 mile square grid (Fig. 8). The simulations are thus robust for the resolutions of the input grid, as expected for a fractal.

The model is also robust to the probability distribution of cell replacements. Rather than a constant prob-

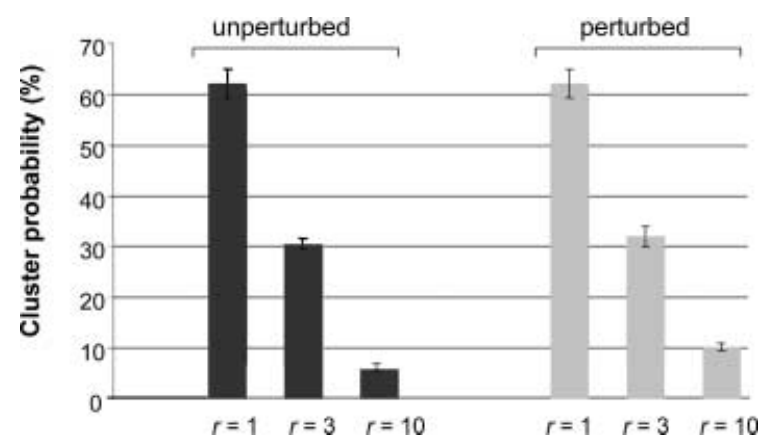

Fig. 6. Perturbation experiment using a proportional $20 \%$ shift in original pattern frequency. The cluster probabilities after convergence of the perturbed and the unperturbed simulation do not statistically differ for the radius sizes of $r=1$ and $r=3$. The perturbed and the unperturbed simulation differ however for $r=10$ as the landscape stays essentially random.

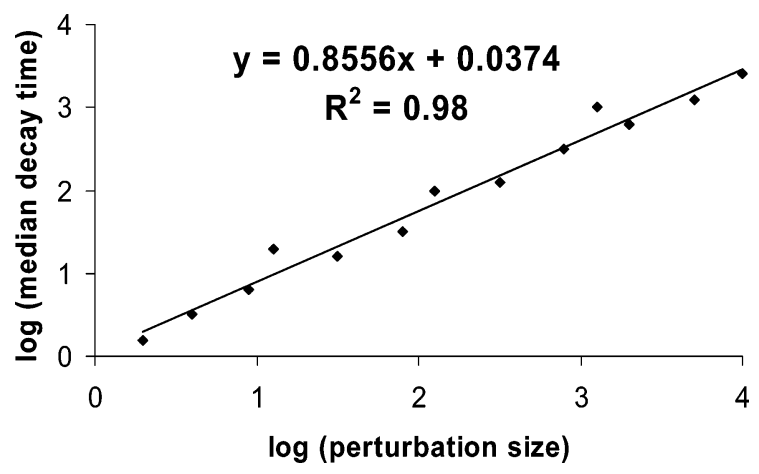

Fig. 7. Perturbation experiment using various perturbation sizes. All sizes of perturbations eventually die out.

ability over the interval zero to $r$, probability kernels that decrease slowly behave similarly including the "small world" limit where a small fraction of the replacements are chosen randomly from throughout the landscape.

\section{Discussion}

The variety of species and numerous interactions among biotic and abiotic factors in ecosystems give rise to complex spatio-temporal patterns. In this paper, we presented an endogenous approach to describe and understand landscape-pattern complexity. As opposed to exogenous approaches where biotic units are largely interpreted as the product of environmental heterogeneity, endogenous approaches view the observed pattern to be a function of internal interactions of the individual system components that generate order by accumulating small changes through time (Bak 1996). The development of the organizing aggregation process eventually gives rise to complex structures. One aspect of complex behavior is the aggregation into distinct spatio-temporal patterns where local rules produce global behavior.

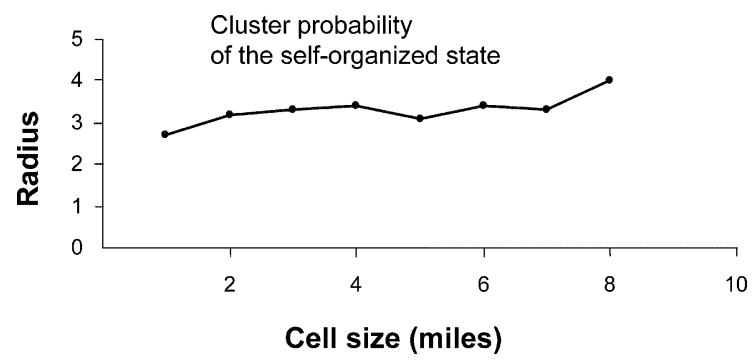

Fig. 8. Test for the dependence on the resolution of the grid size (originally $1 \mathrm{mile}$ ). The data was resampled on coarser resolutions between 2 and 8 miles. 


\section{Simple models may suffice to describe complex landscape patterns}

Prior to Euro-American settlement, the landscape of southern Wisconsin consisted of a mosaic of prairie, savanna, open forest, and closed forest (Curtis 1959, Finley 1976). Early descriptions picture the widespread occurrence of oak-dominated savannas and prairies on hills and dry sites. Common oak species included white (Quercus alba L.), bur (Q. macrocarpa Michx.), and black oaks (Q. velutina Lam.) (Curtis 1959). Sand barrens, a type of savanna and dominated by jack's pine (Pinus banksiana Lamb.) were primarily found on sandy glacial outwash plains. Closed forests, dominated by mesic hardwood forests occurred on richer, welldrained soils in the west and southwest of the state as well as in climatically moderate areas influenced by Lake Michigan. These forests were dominated by sugar maple (Acer saccharum Marsh.) and American basswood (Tilia americana L.), with northern red oak $(Q$. rubra L.), white ash (Fraxinus americana L.) and American beech (Fagus americana Ehrh.). Lowland forests near lakes and rivers were composed of eastern cottonwood (Populus deltoides Bartr. ex Marsh.), black ash (F. nigra Marsh.), silver maple (A. saccharinum L.), and American elm (Ulmus americana L.) (Curtis 1959).

Landscapes are heterogeneous due to a broad variety of processes, ranging from the variability in abiotic conditions (e.g. climate: Iverson and Prasad 1998, Bolliger et al. 2000), to biotic interactions (Ives et al. 1998), human land-use (Russell 1981, 1997, Bürgi et al. 2000, Bürgi and Russell 2001), disturbance such as fire (He and Mladenoff 1999) or insect outbreak (Radeloff et al. 2000a). The historical landscape of southern Wisconsin was structurally very heterogeneous due to the variation of the fire return interval that generates different successional stages (Curtis 1959, Finley 1976, Whitney 1994). Comparatively high frequency of fire disturbance was the most likely factor maintaining historical landscape patterns such as prairies and savannas, whereas low frequencies in fire disturbance caused closed forests to form (Curtis 1959). However, such landscape heterogeneity representing different successional stages can be generated by various drivers depending on the landscape details. For example, the drivers to maintain the heterogeneity of mountainous landscapes may be avalanches rather than fire. In even another landscape wind disturbance may be the driver of successional dynamics, rather than fire or avalanches. Thus similar patterns such as prairies and closed forests occur in completely different environmental settings due to very different drivers. However, in a statistical sense the effects of such processes are similar on landscapes in that the homogenous symmetry of the landscape is broken up into patterns of different properties (e.g. age structure or vegetation types) and a variety of statistical landscape-pattern characteristics are thus largely inde- pendent of their drivers. For modeling at the landscape scale this may indicate that details are not required to describe the general landscape pattern. Thus, very general and simple model parameterization in the sense of low detail requirements, rather than complex model parameterization, may suffice over a wide range of scales. Advantages of simple models include easy control over the behavior of the parameters, as opposed to complex model parameterization whose parameter interactions are difficult to quantify (Rastetter 1991). Limitations of these simple models include exclusively statistical and not spatial representation of the landscape pattern. Also, mechanistic details on the abiotic or biotic drivers cannot be addressed with this type of model.

We presented a generic and process-independent model that is sufficient for generating a complex patterns resembling the historical landscape of southern Wisconsin (USA). The model uses a single, adjustable parameter to mimick low-level interaction processes among the landscape components (patterns). Our results suggest that the simple model yields robust spatiotemporal dynamics on a landscape-scale that are consistent with the apparent statistics. We thus state that models with simple rules that do not specify specific processes may suffice to replicate major characteristics of the landscape pattern originating from complex spatial and temporal interactions.

Process-independent models (neutral models) have played an important role in various fields of ecology, including applied fields: landscape patterning (Gardner et al. 1987), fire disturbance (Turner et al. 1989, Green et al. 1990), effects of habitat fragmentation on birds (Hansen and Urban 1992, Andrén 1994, With and King 1999) or mammals (Andrén 1994), extinction thresholds (Lande 1987), or predictions of the effect of habitatand land-use changes on species (Hansen and Urban 1992, With and Crist 1995), but also in the field of theoretical landscape ecology where the neutral models provide generalized null models to generate patterns in the absence of specific processes (Gardner et al. 1987, Turner et al. 1989, Gardner and O'Neill 1991, With et al. 1997, With and King 1999 but see Schumaker 1996) with the intention to achieve statistical, rather than spatially explicit representations of the landscape under study.

\section{Self-organization and algorithmic complexity to measure landscape-patterns and connectivity}

Our model predicts that generic simple rules (a) create self-organization by driving the dynamics of a landscape so that order emerges spontaneously from different initial conditions, and (b) self-organize to a critical state by presenting the dynamics as scale-free: temporally as power laws and spatially as fractals. Self-orga- 
nization occurs due to gradual aggregation of landscape elements into patterns with identical properties through time. Self-organization is a phenomenon that does not specify causalities between patterns and environment and is generated by internal variation independent of external drivers.

Scale-free behavior is the key phenomenon in nature when defining self-organized critical states (Bak et al 1987, Bak 1996, Solé et al. 1999), and is a phenomenon with strong universal and interdisciplinary character since fractals and power laws are observed throughout nature: earthquakes (Gutenberg and Richter 1954, Ceva 1998), quasar luminosities (Press 1978), avalanches in sand piles (Bak et al. 1987, Bak 1994, 1996), or chemical reactions (Simoyi et al. 1982), diversity (Solé and Manrubia 1995, Caldarelli et al. 1998, Lässig et al. 2001), population dynamics (Hassell et al. 1994, Perry 1995, Kaitala and Ranta 1998, Katiala et al. 2001), fire (Green et al. 1990, Malamud et al. 1998, Song et al. 2001), evolutionary ecology (Bak and Sneppen 1993, Solé et al. 1999), or forest change during the postglacial period (Green 1990). For investigation of landscape patterns, scale-free behavior indicates that results from investigations observed at one spatial scale can be extrapolated to the entire landscape.

Results from our study show that scale-free behavior depends on the neighborhood size within which cells potentially interact, thus emphasizing the relevance of the magnitude and the pattern of communication (connectivity) across the landscape. Connectivity has played a key role as a landscape pattern descriptor in ecology (Taylor et al. 1993, With et al. 1997), particularly for quantification of the functional linkage among individual elements of a landscape. Connectivity is generated either because habitat is physically adjacent or because the dispersal abilities of the organism effectively connect elements across the landscape (Gardner et al. 1987, O’Neill et al. 1988, With and Crist 1995).

Generally, connectivity can be described by the nature of the interactions among the biotic and/or abiotic units. One description is based on the quantification of interactions among system components based on information theory (Manson 2001). Our results show that algorithmic complexity is a valid measure for quantifying landscape complexity since our simulated and observed landscape have similar values and differ from a random landscape.

Another way of characterizing connectivity across landscapes is based on measurements of physical interaction distances of individual cells on the landscape. In our example, small neighborhood sizes of $r=1$ (representing strongly reduced connectivity as small areas are considered) over-organize, indicating that only small fractions of the overall landscape-pattern diversity can be accounted for within small areas. Thus, low connectivity results in small-scale interactions that lead to over-organization since adjacent cells are likely to ex- hibit identical features such as pattern properties. Large neighborhood sizes of $r=10$ (representing high connectivity as large areas are covered), on the other hand, do not organize at all. Thus, within highly connected landscapes, the likelihood of cells meeting cells with similar properties are low within large areas, leading to low organization levels. However, intermediate sizes of neighborhoods $(r=3)$, representing intermediate levels of connection across the landscape with proportionally more interactions from relatively distant cells than from cells nearby, give rise to self-organization to the value of the observed landscape $(32.3 \%)$. Since the intermediate neighborhood of $r=3$ represents a measure of potential connections among cells of the landscapes but also provokes the landscape to self-organize to the critical state, we propose that self-organized criticality can be used to describe the intermediate connectivity of a landscape.

For the historical landscape of southern Wisconsin, for example, fire disturbance is the likely driver for such intermediate connectivity. If a landscape exhibits low connectivity from the onset (e.g. landscape patterned into prairies, savannas, and closed forests), fire will have an impact on some of the patterns, however not on the entire landscape. If a landscape exhibits high connectivity such as in a homogeneously closed forest, the effect of fire results in a reduction of the overall connectivity (i.e., break the symmetry of the landscape into patterns). The reduction of the connectivity usually results in some intermediate levels of connectivity such that fire will spread to some extent, but not burn down the entire landscape. Thus, the self-organized critical state representing intermediate levels of connectivity between the landscape elements and related measures of connectivity such as (a) the percolation threshold (With et al. 1997), or (b) evidence of systems that are intermediately connected between completely ordered and random ("small world" concept) (Watts and Strogatz 1998, Montoya and Solé 2002), may express similar landscape properties.

Advantages of the approach of self-organization encompass the fact that it is a truly interdisciplinary and universal phenomenon. However, limitations with regard to the power laws include that the lower boundary in our study is potentially limited by the finite size of individual trees, whereas the upper boundary may be limited by environmental gradients. The question remains whether environmental gradients are strong enough to overwhelm any self-organizing dynamics. Shortcomings include that only few ecological systems are entirely driven by internal interactions, and that energy throughputs in the system cannot be quantified (Milne 1998). This reveals that the approach is most usefully applied a posteriori and is unable to mechanistically simulate fluxes such as e.g. carbon dioxide through ecosystems. 
Challenges in ecological research include approaches that relate the understanding of individual plant or animal species to higher-level phenomena that can be approximated by general frameworks. Since self-organization is a very universal phenomenon that occurs across a broad range of disciplines, it may serve as a tool to address the understanding of ecosystem complexity and function in a more general framework. The phenomenon of self-organization is a powerful interdisciplinary approach (a) to complete some of the current theoretical frameworks (e.g. metapopulation theory) by investigating how internal interactions (e.g. competition) act together and (b) to improve the understanding of how and why biotic units occur together at their current locations across ecosystems and (c) to assess the relative roles of external (e.g. climate) versus internal drivers (self-organization) in determining the observed system complexity.

Models using simple parameters have been successfully applied to a broad variety of physical systems and evidence increases that models using simple parameters can account for the general behavior of system complexity. Although one might not expect such models to be applicable to ecological systems, whose complexity is often described using details such as environmental drivers (e.g. climate) in their spatio-temporal context, self-organization and critical phenomena are fields where large amounts of system detail are not needed to explain the observed complexity (Gisiger 2001). Evidence has been given that models using simple parameterization have been successful to address theoretical as well as applied questions in e.g. biological evolution (Solé et al. 1999) or habitat conservation (Hansen and Urban 1992, With and Crist 1995).

Acknowledgements - We thank David J. Albers and Monica $\mathrm{G}$. Turner for providing helpful suggestions and comments. This research was funded by a grant of the Swiss Science Foundation for prospective scientists by the University of Bern, Switzerland (Janine Bolliger).

\section{References}

Anderson, R. C. and Anderson, M. R. 1975. The presettlement vegetation of Williamson County, Illinois. - Castanea 40: 345-363.

Andrén, H. 1994. Effects of habitat fragmentation on birds and mammals in landscapes with different proportions of suitable habitat: a review. - Oikos 71: 355-366.

Auclair, A. N. 1976. Ecological factors in the development of intensive-management ecosystems in the midwestern United States. - Ecology 57: 431-444.

Bak, P. 1994. Self-organized criticality: a holistic view of nature. - In: Cowan, G., Pines, D. and Meltzer, D. (eds) Complexity: metaphors, models, and reality. Santa Fe Institute Studies in the Sciences of Complexity, Proc. Volume XIX. Addison-Wesley, Reading, MA, pp. 477-495.

Bak, P. 1996. How nature works: the science of self-organized criticality. - Springer Verlag.

Bak, P. and Sneppen, K. 1993. Punctuated equilibrium and critically in a simple model of evolution. - Physical Rev. Lett. 71: 4083-4086.
Bak, P., Tang, C. and Wiesenfeld, K. 1987. Self-organized criticality: an explanation of $1 / \mathrm{f}$ noise. - Physical Rev. Lett. 59: $381-384$

Beerling, D. J., Woodward, F. I., Lomas, M. and Jenkins, A. J. 1997. Testing the responses of a dynamic global vegetation model to environmental change: a comparison of observations and predictions. - Global Ecol. Biogeogr. Lett. 6: 439-450.

Bolliger, J., Kienast, F. and Zimmermann, N. E. 2000. Risks of global warming on montane and subalpine forests in Switzerland - a modeling study. - Regional Environ. Change 1: 99-111.

Bradbury, R. H., Green, D. G. and Snoad, N. 2000. Are ecosystems complex systems? - In: Bossomaier, T. R. J. and Green, D. G (eds), Complex systems. Cambridge Univ. Press, pp. 339-366.

Brown, D. G. 1994a. Predicting vegetation types at treelines using topography and biophysical disturbance variables. J. Veg. Sci. 5: 641-656.

Brown, D. G. 1998a. Mapping historical forest types in Baraga County, Michigan as fuzzy sets. - Plant Ecol. 134: 97-111.

Brown, D. G. 1998b. Classification and boundary vagueness in mapping presettlement forest types. - Int. J. Geogr. Information Sci. 12: 105-129.

Brown, J. H. 1994b. Complex ecological systems. - In: Cowan, G. A., Pines, D. and Melzer, D. (eds), Complexity: metaphors, models, and reality. Santa Fe Institute Studies in the Sciences of Complexity, Proc. Volume XIX. Addison-Wesley, Reading, MA, pp. 414-449.

Bugmann, H. K. M. 1996. A simplified model to study species composition along climate gradients. - Ecology 77: 20552074

Bürgi, M., Russell, E. W. B. and Motzkin, G. 2000. Effects of post-settlement land-use history on forest composition in the north-eastern United States - a comparative approach. - J. Biogeogr. 27: 1123-1138.

Bürgi, M. and Russell, E. W. B. 2001. Integrative methods to study landscape changes. - Land Use Policy 18: 9-16.

Canham, C. D. and Loucks, O. L. 1984. Catastrophic windthrow in the presettlement forests of Wisconsin. Ecology 65: 803-809.

Caldarelli, G. P., Higgs, P. G. and McKane, A. J. 1998. Modeling coevolution in multispecies communities. - $\mathrm{J}$. Theoret. Biol. 193: 345-358.

Ceva, H. 1998. On the asymptotic behavior of an earthquake model. - Physics Lett. A 245: 413-418.

Clifford, P. and Sudbury, A. 1973. A model for spatial conflict. - Biometrika 60: 581-588

Cottam, G. and Curtis, J. T. 1956. The use of distance measures in phytosociological sampling. - Ecology 37: $451-460$.

Curtis, J. T. 1959. The vegetation of Wisconsin. - The Univ. of Wisconsin Press.

Feldman, D. P. and Crutchfield, J. P. 1998. Measures of statistical complexity: Why? - Physics Lett. A 238: 244 252 .

Finley, R. 1976. The original vegetation of Wisconsin. - PhD Thesis, Univ. of Wisconsin-Madison.

Foster, D. R., Motzkin, G. and Slater, B. 1998. Land-use history as long-term, broad-scale disturbance: regional forest dynamics in central New England. - Ecosystems 1: 96-119.

Gardner, R. H. and O’Neill, R. V. 1991. Pattern, process, and predictability: the use of neutral models for landscape analysis. - In: Turner, M. G. and Gardner, R. H. (eds), Quantitative methods in landscape ecology. Springer-Verlag, pp. 289-307.

Gardner, R. H., Milne, B. T., Turner, M. G. and O’Neill, R. V. 1987. Neutral models for the analysis of broad-scale landscape pattern. - Landscape Ecol. 1: 19-28.

Gisiger, T. 2001. Scale variance in biology: coincidence or footprint of a universal mechanism? - Biol. Rev. 76: $161-209$. 
Grassberger, P. and Procaccia, I. 1983. Characterization of strange attractors. - Physical Rev. Lett. 50: 346-349.

Green, D. G. 1990. Landscapes, cataclysms and population explosions. - Math. Computer Modeling 13: 75-81.

Green, D. G., Tridgell, A. and Gill, A. M. 1990. Interactive simulation of bushfire spread in heterogeneous fuel. Math. Computer Modeling 13: 57-66.

Grimm, E. C. 1984. Fire and other factors controlling the Big Woods vegetation of Minnesota in the mid-nineteenth century. - Ecol. Monogr. 54: 145-164.

Gutenberg, B. and Richter, C. F. 1954. Seismicity of the earth and associated phenomena. - Princeton Univ. Press.

Hansen, A. J. and Urban, D. L. 1992. Avian response to landscape pattern: the role of species life histories. Landscape Ecol. 7: 163-180.

Hassell, M. P., Comins, H. N. and May, R. M. 1994. Species coexistence and self-organizing spatial dynamics. - Nature 370: $290-292$.

He, H. S. and Mladenoff, D. J. 1999. Spatially explicit and stochastic simulation of forest-landscape fire disturbance and succession. - Ecology 80: 81-99.

He, H. S., Mladenoff, D. J., Sickley, T. A. and Guntenspergen, G. G. 2000. GIS interpolation of witness tree records (1839-1866) for northern Wisconsin at multiple scales. - J Biogeogr. 27: 1031-1042.

Holdridge, L. R. 1947. Determination of world plant formations from simple climatic data. - Science 105: 367-368.

Holley, R. and Liggett, T. M. 1975. Ergodic theorems for weakly interacting particle systems in the voter model. Ann. Probability 3: 643-663.

Huntley, B., Berry, P. M., Cramer, W. and McDonald, A. P. 1995. Modelling present and potential future ranges of some European higher plants using climate response surfaces. - J. Biogeogr. 22: 967-1001.

Ives, A. R., Turner, M. G. and Pearson, S. M. 1998. Local explanations of landscape patterns: can analytical approaches approximate simulations models of spatial processes? - Ecosystems 1: 35-51.

Iverson, L. R. and Prasad, A. M. 1998. Predicting abundance of 80 tree species following climate change in the eastern United States. - Ecol. Monogr. 68: 465-485.

Kaspar, F. and Schuster, H. G. 1987. An easily calculable measure for the complexity of spatio-temporal patterns. Physical Rev. A 36: 842.

Kaitala, V. and Ranta, E. 1998. Traveling wave dynamics and self-organization in a spatio-temporally structured population. - Ecol. Lett. 1: 186-192.

Katiala, V., Alaja, S. and Ranta, E. 2001. Temporal self-similarity created by spatial individual-based population dynamics. - Oikos 94: 273-278.

Kirilenko, A. P. and Solomon, A. M. 1998. Modelling dynamic vegetation responses to rapid climate change using bioclimatic classification. - Climatic Change 28: 16-49.

Kline, V. M. and Cottam, G. 1979. Vegetation response to climate and fire in the driftless area of Wisconsin. Ecology 60: 861-868.

Klomp, N. I. and Green, D. G. 1996. Connectivity in landscapes and ecosystems. - In: Stocker, R., Jelinek, H., Bossomaier, T. and Durnota, D. (eds), Complex systems from local interactions to global behaviour. IOS Press, Amsterdam, pp. 46-56.

Lande, R. 1987. Demographic models of the northern spotted owl (Strix occidentalis caurina). - Oecologia 75: 601-607.

Lässig, M., Bastolla, U., Manrubia, S. C. and Valleriani, A 2001. Shape of ecological networks. - Physical Rev. Lett 86: 4418-4421.

Lempel, A. and Ziv, J. 1976. On the complexity of finite sequences. - IEEE Trans. Information Theory 22: 75-81

Malamud, B. D., Morein, G. and Turcotte, D. L. 1998. Forest fires: an example of self-organized critical behavior. Science 281: 1840-1842.

Mandelbrot, B. 1982. The fractal geometry of nature. Freeman.
Manies, K. L. and Mladenoff, D. J. 2000. Testing models to produce landscape-scale presettlement vegetation maps form the U.S. public land survey records. - Landscape Ecol. 15: 741-754.

Manies, K. L., Mladenoff, D. J. and Nordhein, E. V. 2001. Assessing large-scale surveyor variability in the historic forest data of the original US public land survey. - Can. J. Forest Res. 31: 1719-1730.

Manson, S. M. 2001. Simplifying complexity: a review of complexity theory. - Geoforum 32: 405-414.

Mikan, C. J., Orwig, D. A. and Abrams, M. D. 1994. Age structure and successional dynamics of a presettlementorigin chestnut oak forest in the Pennsylvania Piemont. Bull. Torrey Bot. Club 121: 13-23.

Milne, B. T. 1988. Measuring the fractal geometry of landscapes. - Appl. Math. Computation 27: 67-79.

Milne, B. T. 1991. Lessons from applying fractal models to landscape patterns. - In: Turner, M. G. and Gardner, R. H. (eds), Quantitative methods in landscape ecology. Springer, pp. 199-235.

Milne, B. T. 1998. Motivation and benefits of complex systems approaches in ecology. - Ecosystems 1: 449-456.

Mladenoff, D. J. and Howell, E. A. 1980. Vegetation change on the Gogebic Iron Range (Iron County), Wisconsin) form the 1860s to the present. - Trans. Wisconsin Acad Sci., Arts, Lett. 68: 74-89.

Mladenoff, D. J., Dahir, S. E., Schulte, L. A. and Guntenspergen, G. G. 2002. Narrowing historical uncertainty: a probabilistic classification of ambiguously identified tree species in historical forest survey data. - Ecosystems 5: 539-553.

Montoya, J. M. and Solé, R. V. 2002. Small world patterns in food webs. - J. Theoret. Biol. 214: 405-412.

Nelson, J. C. 1997. Presettlement vegetation pattern along the 5th principal meridian, Missouri Territory, 1815. - Am. Midl. Nat. 137: 79-94.

O’Neill, R. V., Krummel, J. R., Gardner, R. H. et al. 1988. Indices of landscape pattern. - Landscape Ecol. 1: 153 162.

Pacala, S. W., Canham, C. D., Saponara, J. et al. 1996. Forest dynamics defined by field measurements: estimation, error analysis and dynamics. - Ecol. Monogr. 66: 1-43.

Perry, D. A. 1995. Self-organizing systems across scales. Trends Ecol. Evol. 10: 241-244.

Prentice, I. C., Cramer, W., Harrison, S. P. et al. 1992. A global biome model based on plant phyiology and dominance, soil properties and climate. - J. Biogeogr. 19: $117-134$

Press, W. H. 1978. Flicker noise in astronomy and elsewhere. - Comments Astrophys. 7: 103-119.

Radeloff, V. C., Mladenoff, D. J., He, H. S. and Boyce, M. S. 1999. Forest landscape change in the northwestern Wisconsin Pine Barrens form pre-European settlement to the present. - Can. J. Forest Res. 29: 1649-1659.

Radeloff, V. C., Mladenoff, D. J. and Boyce, M. S. 2000a. The changing relation of landscape pattern and jack pine budworm populations during an outbreak. - Oikos 90: 417430.

Radeloff, V. C., Mladenoff, D. J. and Boyce, M. S. 2000b. A historical perspective and future outlook on landscape scale restoration in the northwest Wisconsin Pine Barrens. - Restoration Ecol. 8: 119-126.

Rastetter, E. B. 1991. A spatially explicit model of vegetationhabitat interactions on barrier islands. - In: Tuner, M. G. and Gardner, R. H. (eds), Quantitative methods in landscape ecology. Springer-Verlag, pp. 353-378.

Rodgers, C. S. and Anderson, R. C. 1979. Presettlement vegetation of two prairie peninsula counties. - Bot. Gaz. 140: $232-240$

Russell, E. W. B. 1981. Vegetation of northern New Jersey before European settlement. - Am. Midl. Nat. 105: 1-12.

Russell, E. W. B. 1997. People and the land through time: Linking ecology and history. - Yale Univ. Press. 
Schulte, L. A. and Mladenoff, D. J. 2001. The original U.S. Public Land Survey records: their use and limitations in reconstructing presettlement vegetation. - J. Forestry 99: $5-10$.

Schulte, L. A., Mladenoff, D. J. and Nordheim, E. V. 2002 Quantitative classification of a historic northern Wisconsin (USA) landscape: mapping regional forest types and their spatial uncertainty. - Can. J. Forest Res. 32: 1616-1638.

Schumaker, N. H. 1996. Using landscape indices to predict habitat connectivity. - Ecology 77: 1210-1225.

Sickley, T. A. 2000. Pre-European settlement vegetation of Wisconsin, database documentation V1. April 2000. Forest Landscape Ecology Lab, Dept of Forest Ecology and Management, Univ. of Wisconsin-Madison.

Silbernagel, J., Martin, S. R., Gale, M. R. and Chen, J. 1997 Prehistoric, historic, and present settlement pattern related to ecological hierarchy in the eastern upper peninsula of Michigan, USA. - Landscape Ecol. 12: 223-240.

Simoyi, R. H., Wolf, A. and Swinney, H. L. 1982. One-dimensional dynamics in a multicomponent chemical reaction. Physical Rev. Lett. 49: 245-248.

Song, W., Weicheng, F., Binghong, F. and Jianjun, Z. 2001. Self-organized criticality of forest fire in China. - Ecol Modelling 145: 61-68.

Solé, R. V. and Manrubia, S. C. 1995. Are rainforests self-organized to a critical state? - J. Theoret. Biol. 173: 31-40.

Solé, R. V., Bascompte, J. and Valls, J. 1992. Stability and complexity of spatially extended two-species competition. - J. Theoret. Biol. 159: 469-480.

Solé, R. V., Manrubia, S. C., Benton, M. et al. 1999. Criticality and scaling in evolutionary ecology. - Trends Ecol. Evol. 14: 156-160.

Sprott, J. C. and Rowlands, G. 1998. Chaos data analyzer. Physics Academic Software, Raleigh, North Carolina.

Sprott, J. C., Bolliger, J. and Mladenoff, D. J. 2002. Self-organized criticality in forest landscape evolution. - Physics Lett. A 297: 271-276.
Stewart, L. O. 1935. Public land surveys: history, instruction, methods. - Collegiate Press Inc, Ames, Iowa.

Taylor, P. D., Fahrig., L., Henein, K. and Merriam, G. 1993. Connectivity is a vital element of landscape structure. Oikos 68: 571-573.

Turner, M. G., Costanza, R. and Sklar, F. H. 1989a. Methods to compare spatial patterns for landscape modelling and analysis. - Ecol. Modelling 48: 1-18.

Turner, M. G., Gardner, R. H., Dale, V. H. and O'Neill, R. V. 1989. Predicting the spread of disturbance across heterogeneous landscapes. - Oikos 55: 121-129.

Wallin, D. O., Swanson, F. J., Marks, B. et al. 1996. Comparison of managed and pre-settlement landscape dynamics in forest of the Pacific Northwest, USA. - Forest Ecol. Manage. 85: 29-309.

Watts, D. J. and Strogatz, S. H. 1998. Collective dynamics of 'small-world' networks. - Nature 393: 440-442.

White, M. A. and Mladenoff, D. J. 1994. Old-growth forest landscape transitions from pre-European settlement to present. - Landscape Ecol. 9: 191-205.

Whitney, G. G. 1994. From coastal wilderness to fruited plain. - Cambridge Univ. Press.

With, K. A. and Crist, T. O. 1995. Critical thresholds in species' responses to landscape structure. - Ecology 76: $2446-2459$

With, K. A. and King, A. W. 1999. The use and misuse of neutral landscape models in ecology. - Oikos 79: 219-229.

With, K. A., Gardner, R. H. and Turner, M. G. 1997. Landscape connectivity and population distributions in heterogeneous environments. - Oikos 78: 151-169.

Zhang, Q., Pregitzer, K. S. and Reed, D. D. 1999. Historical changes in the forests of the Luce District of the Upper Peninsula in Michigan. - Am. Midl. Nat. 143: 94-110.

Zimmermann, N. E. and Kienast, F. 1999. Predictive mapping of alpine grasslands in Switzerland: species versus community approach. - J. Veg. Sci. 10: 469-482. 